Tohoku J. Exp. Med., 2003, 201, 213-219

\title{
Partial Regeneration/Proliferation of the $\beta$-Cells in the Islets of Langerhans by Nigella sativa L. in Streptozotocin-Induced Diabetic Rats
}

\author{
Mehmet Kanter, Ismail Meral, ${ }^{1}$ Zabit $_{\text {Yener }}{ }^{2}$ Hanefi $_{\text {OzBeK }}{ }^{3}$ and Halit \\ $\operatorname{DEMIR}^{4}$ \\ Department of Histology-Embryology, ${ }^{1}$ Department of Physiology, ${ }^{2}$ Department \\ of Pathology, Veterinary Medicine, ${ }^{3}$ Department of Pharmacology, Medical \\ School, ${ }^{4}$ Department of Chemistry, Faculty of Art and Science, Yuzuncu Yil \\ University, Van, Turkey
}

Kanter, M., Meral, I., Yener, Z., Ozbek, H. and Demir, H. Partial Regeneration/Proliferation of the $\beta$-Cells in the Islets of Langerhans by Nigella sativa L. in Streptozotocin-Induced Diabetic Rats. Tohoku J. Exp. Med., 2003, 201 (4), 213-219 — This experiment was carried out to investigate the effect of $N$. sativa L. on histopathology of pancreatic $\beta$-cells, and blood insulin and glucose concentrations in streptozotocin-induced diabetic rats. Fifty male Wistar rats (200-250 g) were divided into two experimental groups (diabetics with no treatment and diabetics with $N$. sativa L.treatment), each containing twenty-five rats. Diabetes was induced in both groups by a single intraperitoneal injection of streptozotocin (STZ) (50 mg/kg). The experimental animals in both groups became diabetic within 24 hours after the administration of STZ. The rats in $N$. sativa L.-treated group were given the daily intraperitoneal injection of $0.20 \mathrm{ml} / \mathrm{kg}$ of $N$. sativa $\mathrm{L}$. volatile oil for 30 days starting the day after STZ injection. Control rats received only the same amount of normal saline solution. The rats in both groups received the last injection 24 hours before the sacrification and 5 randomly-selected rats in each group were sacrificed before, and the 1,10,20 and 30 days after the STZ injection to collect blood and pancreatic tissue samples. The $N$. sativa L. treatment caused a decrease in the elevated serum glucose, an increase in the lowered serum insulin concentrations and partial regeneration/proliferation of pancreatic $\beta$-cells in STZ-induced diabetic rats with the elapse of the experiment. It is concluded that the hypoglycaemic action of $N$. sativa L. could be partly due to amelioration in the $\beta$-cells of pancreatic islets causing an increase in insulin secretion. More studies are needed to demonstrate the exact mechanism of action of $N$. sativa L. on ameliorated blood glucose concentration in STZ-induced diabetes. — rats; $N$. sativa L.; glucose; insulin, $\beta$-cells

(C) 2003 Tohoku University Medical Press

Received March 12, 2003; revision accepted for publication October 17, 2003.

Address for reprints: Ismail Meral, Ph.D., Yuzuncu Yil Universitesi, Veteriner Fakultesi, Fizyoloji

Anabilim Dali, 65080, Kampus, Van, Turkey.

e-mail: imeral20@ hotmail.com 
Diabetes mellitus (DM) is one of the most common metabolic disorders, with a world-wide prevalence estimated to be between $1 \%$ and $5 \%$. The increasing prevalence of DM in the world is a cause for concern. Thus, we have been investigating the amelioration of experimentallyinduced diabetes by the extract of $N$. sativa L. seeds for the past two years. During this time a marked amelioration was observed in diabetes-induced disturbances of thyroid hormone metabolism (Meral et al. 2003), serum glucose and lipid peroxide levels, and liver damage (Meral et al. 2001).

$N$. sativa L. is a spice plant belonging to the family Ranunculaceae (Aqel and Shaheen 1996). It is a medical plant that contains black seeds and has been used as a natural remedy for a variety of illness. It has been shown that $N$. sativa L. contains $>30 \%$ of a fixed oil and 0.40 $0.45 \%(\mathrm{w} / \mathrm{w})$ of a volatile oil (VO). The VO has been shown to contain $18.4-24 \%$ thymoquinone and $46 \%$ many monoterpenes such as p-cymene, and $\alpha$-pinene (El-Tahir et al. 1993a), and to have bronchodilator (El-Tahir et al. 1993b), antibacterial (Hanafy and Hatem 1991), diuretic and hypotensive (Zaoui et al. 2000), and immunopotentiating (El-Kadi and Kandil 1987) activities.

This experiment was carried out to investigate the effect of $N$. sativa $\mathrm{L}$. on histopathology of pancreatic $\beta$ cells, and blood insulin and glucose concentrations in streptozotocin (STZ)induced diabetic rats.

\section{MATERIALS AND METHODS}

\section{Isolation of $N$. sativa $L$. volatile oil}

The $N$. sativa L. seeds were purchased from a local herb store, authenticated by Dr. Fevzi Ozgokce, Department of Botany, University of Yuzuncu Yil, washed and air-dried. A voucher specimen (F-5427b) has been kept in the VANF herbarium for the future reference. The seeds were powdered in a mixer, placed in a distillation flask and the oil with $0.2 \%$ yield was collected by a steam distillation.

\section{Acute toxicity test}

Male White Albino mice (20-24 g) were randomly assigned to 6 groups (T1, T2, T3, T4, T5 and T6) with 8 animals in each group. First group (T1) was treated with normal saline solution and considered as control. Other five groups were treated with the aqueous extract given intraperitoneally in increasing dosages of $0.25,0.50,1.0,2.0$ and $4.0 \mathrm{ml} / \mathrm{kg}$. The maximum volume injected was $0.2 \mathrm{ml}$. The groups were returned to their home cages and given free access of food and water. The mortality in each cage was assessed 24 hours, 48 hours and 72 hours after administration of the extract. The percentage mortalities were converted to probits and plotted against the $\log _{10}$ of the extract dose. Regression lines were fitted by the method of least squares and confidence limits for the lethal dose $\left(\mathrm{LD}_{50}\right)$ values were calculated by the method of Litchfield and Wilcoxon (1949) and Abdel-Barry et al. (1997).

\section{Experimental design}

Fifty male Wistar rats (200-250 g) were used in this study. Rats were divided into two experimental groups (diabetics with no treatment and diabetics with $N$. sativa L. treatment), each containing twenty-five rats. The rats were housed individually in macrolon cages under standard laboratory conditions (light period $7: 00$ a.m. to $7: 00$ p.m., $21 \pm 1^{\circ} \mathrm{C}$, rat chow and tap water freely available). Diabetes was induced in both groups by a single intraperitoneal injection of STZ $(50 \mathrm{mg} / \mathrm{kg}$, freshly dissolved in $5 \mathrm{mmol} /$ liter citrate buffer, $\mathrm{pH}$ 4.5). The experimental animals in both groups became diabetic within 24 hours after the administration of STZ. The diabetes mellitus was confirmed by Ames One Touch Glucometer (LifeScan, Johnson and Johnson, New Brunswick, NJ, USA) and only animals with glucose $\geqq 300 \mathrm{mg} / 100 \mathrm{ml}$ were considered as diabetic. The rats in N. sativa L.-treated group were given the daily intraperitoneal injection of 
$0.20 \mathrm{ml} / \mathrm{kg}$ of $N$. sativa L. VO for 30 days starting the day after STZ injection. Control rats, on the other hand, received only the same amount of normal saline solution. The rats in both groups received the last injection 24 hours before the sacrification and 5 randomly-selected rats in each group were sacrificed before, and the 1,10,20 and 30 days after the STZ injection to collect blood and pancreatic tissue samples. The rats received humane care according to the criteria outlined in the "Guide for the Care and Use of Laboratory Animals" prepared by the National Academy of Sciences and published by the National Institutes of Health.

\section{Biochemical procedures}

Five randomly-selected rats in each group were anaesthetised with intraperitoneal injection of chloralhydrate $(6 \mathrm{ml}$ of $7 \%$ chloralhydrate $\mathrm{kg}$ ) before, and the 1, 10, 20 and 30 days after the STZ injection. Under chloralhydrate anaesthesia, each rat was sacrificed by cardiac puncture to collect blood samples using heparinised syringe. Serum glucose was determined by hexokinase method with reagents from Boehringer (Mannheim, Frankfurt, Germany), and insulin was determined by a doubleantibody radioimmunoassay kit (Amersham Radiochemical Centre, Bucks, UK).

\section{Histopathological procedures}

Pancreatic tissues were harvested from the sacrificed animals before, and the 1,10,20 and 30 days after the STZ injection, and the fragments from pancreatic tissues were fixed in 10\% neutral buffered formaline, embedded in paraffin and then, stained with haematoxylin and eosin. In addition, van Gieson, Periodic Acid Schiff (PAS) and Oil Red O methods were also used, and histological specimens were examined in light microscopy.

\section{Immunohistochemical procedures}

Harvested pancreatic tissues fixed in 10\% neutral buffered formaline were embedded in paraffin and sectioned at $5 \mathrm{~mm}$ thickness. Immunocytochemical reactions were performed using the Avidin-biotin Complex (ABC) technique according to $\mathrm{Hsu}$ et al. (1981). Specific monoclonal mouse antibody against human insulin protein (Zymed 18-0066, Zymed Laboratories, Inc., South San Francisco, CA, USA) were applied at a dilution of $1: 50$. The procedure was performed by the following steps: 1) inhibition of endogenous peroxidase activity was inhibited with $3 \% \mathrm{H}_{2} \mathrm{O}_{2}$ in distilled water for 30 minutes, 2) washing in tap water for 30 minutes and in distilled water for 10 minutes, 3) blocking of non-specific binding of antibodies by incubation with normal goat serum (DAKO X 0907, DAKO Diagnostics S.A., Barcelona, Spain) with Phosphate Buffered Saline (PBS), diluted $1: 4,4)$ incubation with monoclonal mouse antibody against human insulin protein, diluted $1: 400$ for 2 hours, then at room temperature, 5) washing in PBS $3 \times 3$ minutes, 6) incubation with biotinylated anti-mouse IgG (DAKO LSAB 2 Kit, 7, DAKO Diagnostics S.A.) washing in PBS $3 \times 3$ minutes, 8 ) incubation with ABC complex (DAKO LSAB 2 Kit, DAKO Diagnostics S.A.), 9) washing in PBS $3 \times 3$ minutes, 10) peroxidase detection using amino-9ethyl carbasole, 11) washing in tap water for 10 minutes, dehydration, 12) nuclei staining with hematoxylin, and 13) sections mounting in DAKO faramount.

\section{Statistical analysis}

The data were expressed as mean with standard deviation (S.D.). Student's $t$-test was used to compare $N$. sativa L.-treated vs. control rats.

\section{RESULTS}

Acute toxicity test

The intraperitoneal medium LD50 value of $N$. sativa $\mathrm{L}$. extract for the total number of animals was found to be $0.50 \mathrm{ml} / \mathrm{kg}$. 


\section{Biochemical findings}

$N$ sativa L. treatment caused a decrease $(p<0.001)$ in the elevated serum glucose (Fig. 1) and an increase $(\phi<0.05)$ in the lowered serum insulin (Fig. 2) concentrations in STZ-induced diabetic rats with the elapse of the experiment.

\section{Histopathological findings}

In diabetic rats with no treatment, the most consistent findings in the histologic sections of pancreatic tissues stained with haematoxylin and eosin were the degenerative and necrotic changes, and shrunken in the islets of Langerhans (Fig. 3a). The nucleus of necrotic cells showed either pyknosis or marginal hperchromasie. There was mostly hydropic degeneration and degranulation in the cytoplasm of the degenerative and necrotic cells, while the some of cells with pyknotic nucleus had the

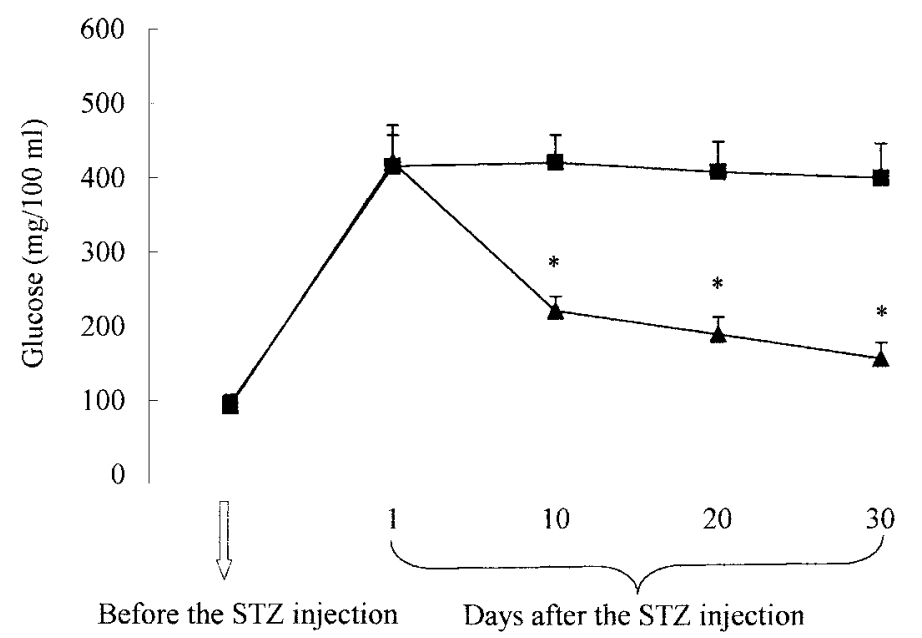

Fig. 1. Serum glucose concentration of control and $N$. sativa L.-treated rats before and after the STZ injection. The data are expressed as mean with s.D.

*Denotes a significant difference $(p<0.001)$ between the control and treatment group.

$\boldsymbol{\square}$, Diabetics with no treatment; $\boldsymbol{\Delta}$, Diabetics with $N$. sativa L. treatment. $n=5$.

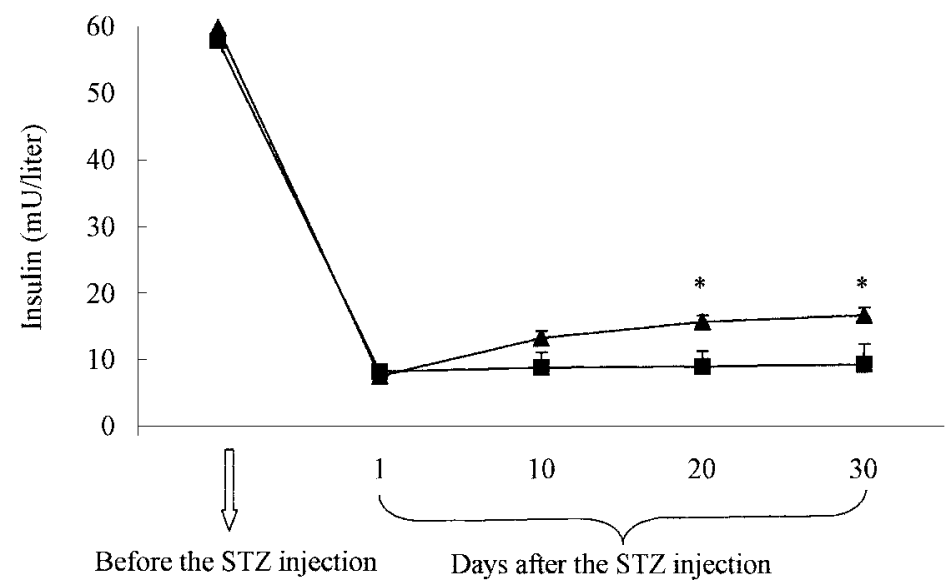

Fig. 2. Serum insulin concentration of control and N. sativa L.-treated rats before and after the STZ injection. The data are expressed as mean with s.D.

*Denotes a significant difference $(\phi<0.05)$ between the control and treatment group.

$\boldsymbol{\square}$, Diabetics with no treatment; $\boldsymbol{\Delta}$, Diabetics with $N$. sativa L. treatment. $n=5$. 
a

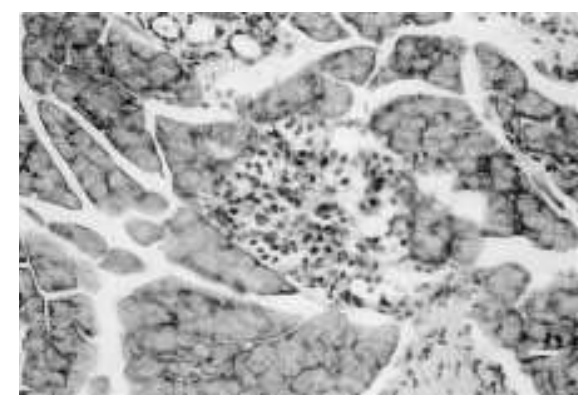

b

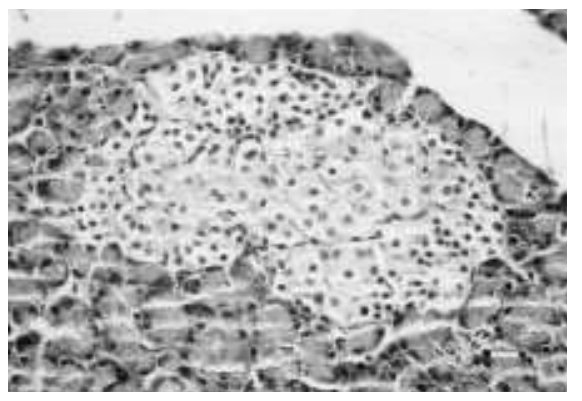

Fig. 3. Histopathology of islets of Langerhans (H \& E; bar, $18 \mu \mathrm{m}$ ).

(a) Shrunken islets of Langerhans displaying degenerative and necrotic changes in diabetic rats with no treatment. (b) Islets of Langerhans displaying increase in size and light degenerative changes in the majority of cells of diabetic rats with 30 days of $N$. sativa L. treatment.

a

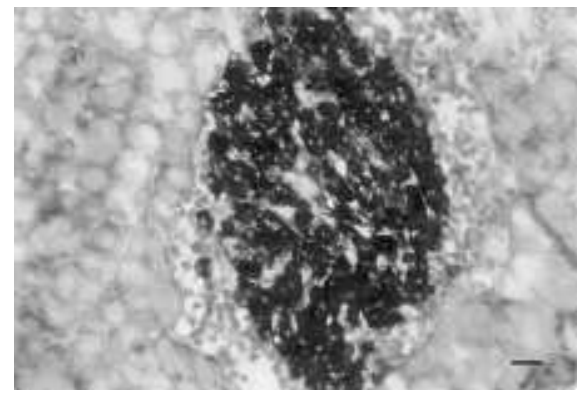

c

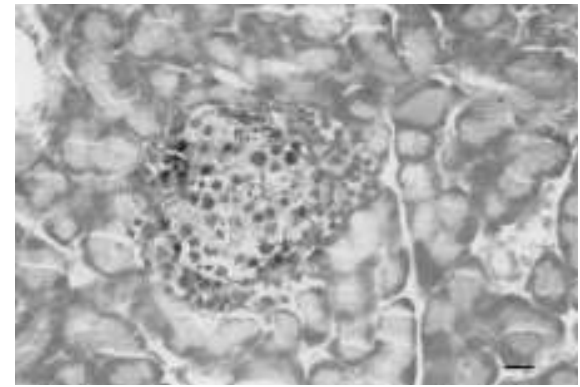

e

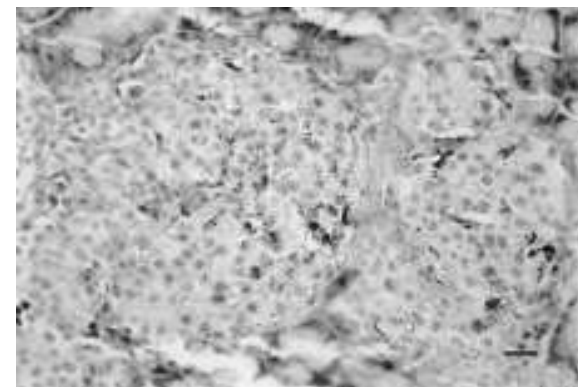

$\mathrm{b}$

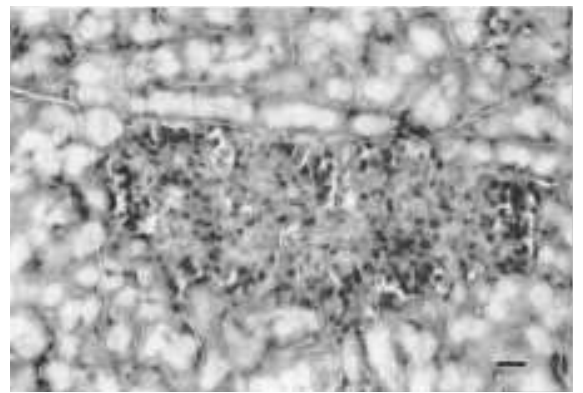

d

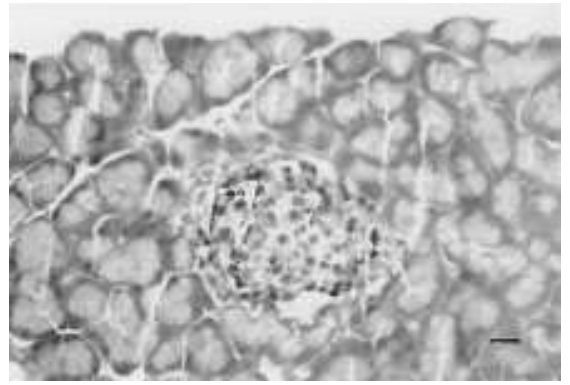

Fig. 4. Immunohistochemical stainings of the pancreatic tissues (bar, $18 \mathrm{~mm}$ ). (a) Strong insulin antigen positivity in $\beta$-cells of rats prior to the STZ injection. Immunoperoxidase, haematoxylin counterstain. (b) Absolute negativity for insulin-immunoreactive $\beta$-cells in the islet of Langerhans of diabetic rats with no treatment. Immunoperoxidase, haematoxylin counterstain. (c) A few $\beta$-cell in some islets displaying the insulin-immunopositivity in very small granules of diabetic rats with $N$. sativa L. treatment on the 10th day of the experiment. Immunoperoxidase, haematoxylin counterstain. (d) Increased number of insulin-immunoreactive $\beta$ cells and granules of diabetic rats with $N$. sativa L. treatment on the 20th day of the experiment. Immunoperoxidase, haematoxylin counterstain. (e) Insulin-immunoreactive $\beta$-cells increased distinctly in number and displayed intense immunostaining on the 30th day when compared to 10th and 20th days of the experiment. Immunoperoxidase, haematoxylin counterstain. 
dark eosinophilic cytoplasm (coagulation necrosis). The degenerative cells were PAS and Oil Red $\mathrm{O}$ negative, indicating the absence of lipid and glycogen.

In diabetic rats treated with $N$. sativa L., the severity of degenerative and necrotic changes in the islet of Langerhans parenchyma was less on the 10th day than those in the diabetic group. On the 20th and 30th days of the experiment, in spite of a few cells with pyknotic nucleus, the majority of cells showed significantly light hydropic degeneration as compared to islets of diabetics with no treatment, partly indicating the regranulation of islet cells (Fig. 3b). The islets of Langerhans were distinctly increased in size. There was also lymphoid cell infiltration in the peripheral parts of the islets of Langerhans in diabetic rats with $N$. sativa L. treatment.

\section{Immunohistochemical findings}

In immunohistochemical staining of the pancreatic tissues of rats before the STZ injection, strong insulin antigen positivity was observed in the $\beta$-cells of the islets (Fig. 4a). In diabetic rats with no treatment there was absolutely negativity for insulin-immunoreactive $\beta$-cells in the islet of Langerhans (Fig. 4b). In diabetic rats treated with $N$. sativa L., a few $\beta$-cell in some islets displayed insulinimmunopositivity in very small granules on the 10th day of the experiment (Fig. 4c). On the 20 th day of the experiment, both the number of insulin-immunoreactive $\beta$-cells and their granules increased (Fig. 4d). On the 30th day of the experiment, insulin-immunoreactive $\beta$-cells increased distinctly in number (Fig. 4e) and displayed intense immunostaining when compared to 10th and 20th days of the experiment.

\section{DISCUSSION}

The antibiotic STZ has a $\beta$-cell cytotoxic effect and a slight carcinogenic effect (Evans et al. 1965). Although the $\beta$-cell cytotoxic action of STZ is not fully understood, it is though to be mediated by the inhibition of free radical scavenger-enzymes thereby enhancing the production of the superoxide radical. The latter has been implicated in lipid oxidation, DNA damage, and sulfhydryl oxidation. In the present study, almost all insulin-positive $\beta$-cells were degranulated, degenerated or necrosed in the STZ treated rats leading a decrease in insulin secretion and an increase in blood glucose concentration.

$N$. sativa L. treatment caused a decrease in the elevated serum glucose and an increase in the lowered serum insulin concentrations in STZ-induced diabetic rats with the elapse of the experiment. In our preliminary study, we had already demonstrated the marked ameliorative effect of $N$. sativa L. extract in increased serum glucose concentration of alloxan-induced diabetic rabbits (Meral et al. 2001). Similar to our results, it has been suggested that $N$. sativa L. possessed blood glucose lowering effects in STZ diabetic rats (El-Dakhakhny et al. 2002). However, present study is the first one that shows a partial amelioration in the $\beta$-cells of pancreatic islets in diabetic rats. It has been suggested that the active principles from plant sources might act by several mechanism such as stimulating insulin secretion, increasing repair/proliferation of $\beta$-cells, enhancing the effect of insulin and adrenaline and increasing the oxidative capability (Shanmugasundaram et al. 1990; Fayed et al. 1998). Our results indicated that decreased blood glucose concentration by $N$. sativa $\mathrm{L}$. treatment might be due to the partial regeneration/proliferation in the pancreatic $\beta$-cells. However, extrapancreatic mechanisms such as enhanced glucose transport into the cells and improved formation of glycogen in the liver might be involved in the $N$. sativa L.-induced decrease in blood glucose concentration of STZ diabetic rats.

It is concluded that the hypoglycaemic action of $N$. sativa L. could be partly due to amelioration in the $\beta$-cells of pancreatic islets causing an increase in insulin secretion. More 
studies are needed to demonstrate the exact mechanism of action of $N$. sativa $\mathrm{L}$. on ameliorated blood glucose concentration in STZinduced diabetes.

\section{References}

Abdel-Barry, J.A., Al-Hakiem, M.H.H. \& AbdelHassan, I.A. (1997) Acute intraperitoneal toxicity $\left(\mathrm{LD}_{50}\right)$ and target organ effects of aqueous extract of Trigonella foenumgraecum leaf in the mause. Basrah J. Sci. Section B, Biology, 58, C58-C65.

Aqel, M. \& Shaheen, R. (1996) Effects of volatile oil of Nigella sativa seeds on the uterine smooth muscle of rat and guinea pig. J. Ethnopharmacol., 52, 23-26.

El-Dakhakhny, M., Mady, N., Lembert, N. \& Ammon, H.P. (2002) The hypoglycemic effect of Nigella sativa oil is mediated by extrapancreatic actions. Planta Med., 68, 465-466.

El-Kadi, A. \& Kandil, O. (1987) The black seed (Nigella sativa) and immunity: its effect on human T cell subset. Fed. Proc., 46, 1222.

El-Tahir, K.E.H., Ashour, M.M.S. \& Al-Harbi, M.M. (1993a) The cardiovascular actions of the volatile oil of the black seed (Nigella sativa) in rats: Elucidation of the mechanism of action. Gen. Pharmacol., 24, 1123-1131.

El-Tahir, K.E.H., Ashour, M.M.S. \& Al-Harbi, M.M. (1993b) The respiratory effects of the volatile oil of the black seed (Nigella sativa) in guinea-pigs: Elucidation of the mechanism(s) of action. Gen. Pharmacol., 24, 1115-1122.

Evans, J.S., Gerritsen, G.C., Mann, K. \& Owen, S.P. (1965) Anti-tumour and hyperglycaemic activity of Streptozotocin (NSC 37917) and its cofactor (U15774). Canc. Chemother. Rep., 48, $1-6$.
Fayed, T., El-Missiry, M.A., Emara, H. \& El-Sayaad, N. (1998) Effect of Nigella sativa or fish oil supplementation in alloxan diabetic rats. $J$. Union. Arab. Biol., 9, 237-250.

Hanafy, M.S.M. \& Hatem, M.E. (1991) Studies on the antimicrobial activity of Nigella sativa seed (black cumin). J. Ethnopharmacol., 34, 275-278.

Hsu, S.M., Raine, L. \& Fanger, H. (1981) Use of Avidin-Biotin-Peroxidase complex $(\mathrm{ABC})$ in immunperoxidase techniques: a comparison between $\mathrm{ABC}$ and unlabeled antibody (PAP) procedures. J. Histochem. Cytochem., 29, 577580.

Litchfield, J.T. \& Wilcoxon, F.W.J. (1949) A simplified method of evaluating dose-effect experiments. J. Pharmacol. Exp. Ther., 96, 99-113.

Meral, I., Yener, Z., Kahraman, T. \& Mert, N. (2001) Effect of Nigella sativa on glucose concentration, lipid peroxidation, antioxidant defence system and liver damage in experimentallyinduced diabetic rabbits. J. Vet. Med. A, 48, 593-599.

Meral, I., Yener, Z., Ozbek, H. \& Ustun, R. (2003) Effects of Nigella sativa L. on serum concentrations of thyroid hormones, thyroid stimulating hormone and glucose in alloxaninduced diabetic rabbits. Irish Vet. J., $\mathbf{5 6}$, 462-464.

Shanmugasundaram, E.R., Gopianth, K.L., Radha, S.K. \& Rajendram, V.M. (1990) Possible regeneration of the islets of langerhans in streptozotocin diabetic rats given Gymnema sylyestra leaf extracts. J. Ethnopharmacol., 30, 265-279.

Zaoui, A., Cherrah, Y., Lacaille-Dubois, M.A., Settaf, A., Amarouch, H. \& Hassar, M. (2000) Diuretic and hypotensive effects of Nigella sativa in the spontaneously hypertensive rat. Therapie, 55, 379-382. 